\title{
Potentials in Udeskole: Inquiry-Based Teaching Outside the Classroom
}

\author{
Karen S. Barfod ${ }^{*}$ and Peer Daugbjerg \\ Department of Teacher Education, VIA University College, Nørre Nissum, Denmark
}

Most research on outdoor education, including the Scandinavian concept udeskole (regular curriculum-based teaching outside the classroom), has focused on pupils' outcomes, whereas less has focused on teachers' practices. In this article, we described the occurrence of inquiry-based teaching in udeskole. To analyze practice, we extended the notion of inquiry-based education. Within science and mathematics education, a strong stepwise teaching approach formerly was established, called Inquiry Based Science and Mathematics Education (IBSME), emphasizing pupils' hypothesis testing, data validation and systematic experimentation. In this study, we broadened the IBSME-concept of inquiry in order to include a more holistic, non-linear teaching approach, but excluding teacher-instructed inquiry. Using this idea, we observed and documented by field notes how five experienced teachers practiced mathematics and science teaching in udeskole at primary level in Denmark. Twenty-eight outdoor days were observed. Each day was divided into separate teaching incidents with a

OPEN ACCESS

Edited by:

Ming Kuo,

University of Illinois at Urbana-Champaign, United States

Reviewed by: Ulrich Dettweiler, University of Stavanger, Norway Christoph Becker, Technische Universität München,

Germany

${ }^{*}$ Correspondence: Karen S. Barfod ksba@via.dk

Specialty section: This article was submitted to Educational Psychology, a section of the journal Frontiers in Education

Received: 04 December 2017 Accepted: 30 April 2018 Published: 22 May 2018

Citation: Barfod KS and Daugbjerg P (2018) Potentials in Udeskole: Inquiry-Based Teaching Outside the Classroom. Front. Educ. 3:34 doi: 10.3389/feduc.2018.00034 distinct start and end. The level of teacher interference and possible choices in each teaching incidents formed the analytic background. We analyzed each of the 71 teaching incidents, and categorized each of them into one of five categories numbered $4-0$. The categories designated numbers 4-2 contained the inquiry-based teaching incidents, and the categories designated 1 and 0 were categorized as "non-inquiry-based." They contained teaching incidents where the teacher was instructing the pupils (category 1), and outdoor teaching activities with no sign of inquiry, called training activities (category 0). Our results showed that about half of the analyzed outdoor teaching practice seemed to be inquiry-based, emphasizing pupils' choice and presenting cognitive challenge. This indicates that the analyzed udeskole had the potential to support an explorative and multifaceted inquiry-based teaching in mathematics and science, paving the way for a child-activating education. These results, albeit limited by the small number of observed teachers, supports the theoretical notion that udeskole is a potential way to strengthen pupils' approach to inquiry.

Keywords: inquiry-based teaching, pupils choices, teacher guidance, teaching outside the classroom, udeskole

\section{INTRODUCTION}

Teaching outside the classroom (TOtC) was discussed as a powerful way to teach curricular content (Rickinson et al., 2004; Becker et al., 2017) in natural and cultural settings. This could imply open-ended problem-solving tasks, involving inquiry-based educational approaches where by pupils were given an element of free choice (Braund, 2004; Jordet, 2010). Inquiry-based teaching has be seen as a part of a historical wave in the educational system (Albrechtsen and Qvortrup, 2017), reversing science teaching from deductive to more pupil-centered teaching, 
emphasizing pupil activity in a constructivist learning process. Inquiry-based teaching was in this perspective both a method for learning certain content and an approach to a field, recognizing the tentative and social parts of science and mathematics (Van Uum et al., 2016).

\section{Inquiry-Based Education in Science and Mathematics}

As it was widely used in science education, discussion concerning the concept of inquiry was prevalent (Artigue and Blomhøj, 2013; Pedaste et al., 2015) and ongoing. Still, a dominant understanding of inquiry in science and mathematics education called IBSE or IBSME was connected to stepwise processes, divided and ordered in distinct phases (Bybee et al., 2006; Pedaste et al., 2015). The phases were referred to differently in the literature, but comprised orientation, conceptualization (questioning, hypothesis generation), investigating (planning, exploration, experimentation, observation and data interpretation, analysis), conclusion, and discussion (with communication and reflection). Whenever these phases were conducted as group-work, we acknowledged this tradition, and suggested that the constructivist starting point was kept, but we added an emphasis to the educational dynamics emerging from the variation in pupils' approaches to learning activities, based on their experiences, among other things.

The aim of this paper was to investigate the prevalence of inquiry-based teaching outside the classroom. First, we discuss the traditional IBSME phases as related but not ordered, acknowledging experiences and pupils' choice as inevitable parts of the inquiry. On basis of this discussion, we propose a framework for analyzing inquiry-based teaching. Second, we use this framework to provide empirical data on the level of teacher guidance during the inquiry process in udeskole.

\section{Inquiry-Based Teaching}

Inquiry has been defined in a broad manner (Artigue and Blomhøj, 2013). In this understanding, inquiry encompassed a variety of practices in a constructivist pedagogical tradition, accentuating pupil activity and engagement. Besides this, the epistemological starting point concerned the democratic and critical part of inquiry, as the ability to solve unknown problems by thinking and reacting autonomously was emphasized. A key feature of inquiry was to develop a problem-based culture, allowing various ways to solve problems (Artigue et al., 2012). Other researchers within inquiry-based learning also underlined how pupils had to be offered necessary and meaningful choices during the process (Bromley et al., 2013). To qualify as choice in the process of solving a task, "the learner must perceive that there are reasonable and desirable learning choices (as defined by the learner) available" (Falk, 2005, p. 747). In this understanding, inquiry was not merely a method but a pedagogical approach, aiming to drive learning through questions and curiosity (Leat, 2017). This approach could support pupils' long-lasting intrinsic motivation to learn (Saunders-Stewart et al., 2012). In our understanding of this line of research on inquiry, experience and sensory perceptions, building up silent knowledge was a key element in an "orientation" phase. Thus, non-conscious, non-cognitive impressions did build up a scaffold for learning. Considering this scaffold helped us to understand how students learn by involving sense experiences, emotions and uncertainties (Hwang and Roth, 2011). This understanding of learning opened up for more than rational scholastic processes by which teachers supported pupils' inquiry work; it also includes pupils' engagement with concrete objects and phenomena from their everyday experience of their world, supporting their curricular learning. This everydayness could constitute both the context for learning, and a resource in the learning process (Jordet, 2010; Hwang and Roth, 2011).

In short, we used the following criteria to recognize inquiry in the teaching activities as: When a sensory or action based experience offered resonance for the learning process, or when the pupils were offered significant choices (in means of process or product) during the learning process.

\section{Teacher Guidance and Free-Choice Learning}

Inquiry-based learning has been described with both a cognitive dimension and a dimension related to teacher guidance (Furtak et al., 2012). When the assignments were open-ended, the teaching offered pupils opportunities to make conscious and meaningful choices (Katz and Assor, 2007), with activities being "open to an autonomous orientation of the student, what increases the possibility of him to produce interpretations and outcomes unexpected for the teacher" (Tavares et al., 2015, p. 157). Activating the part of the cognitive dimension called the "procedural inquiry" (Furtak et al., 2012, p. 305) implied "the mobilization of previous knowledge and the construction of new knowledge" (Tavares et al., 2015, p. 155). Falk (2005) introduced the concept of free-choice learning as an alternative to the dichotomy of formal and informal/non-formal learning, emphasizing that it was hardly the place or institutional context that defined the type of learning, but rather the extent to which the teaching was open-ended, inquiry-based, and optional. Free-choice learning was a construct, as "The operational issue is perceived choice and control by the learner. To qualify as free-choice learning, the learner must perceive that there are reasonable and desirable learning choices (as defined by the learner) available, and that $\mathrm{s} / \mathrm{he}$ possesses the freedom to select (or not to select) from among those choices" (Falk, 2005, p. 273). The concept recognized characteristics of learning as nonsequential, self-paced and voluntary (Falk, 2005), and the socially constructed nature of learning. Based on observation of class visits in museal settings, Bamberger and Tal (2007) identified the constituents of choice the pupils encountered at the visits. From the guided tour with no choices, to levels of limited choice with choices regarding what to work with (topic), where to go (space), what to learn about (object), for how long (time), with whom (friends, instructors, teachers), and with what kind of interactions (interactions) and in what order, tasks could be done (order). At the other end of the spectrum was the free exploration of the exhibition. Unsurprisingly, it was indicated that the effectiveness of learning, measured as the ability to give correct answers on worksheets at the museum, was enhanced by the limited choice 
visits. In these visits, the pupils were offered scaffolding by the teacher, enhancing the pupil's engagement, by allowing the pupils more control over their learning process (Bamberger and Tal, 2007). In inquiry-based teaching, the pupil could make a choice regarding method (Bromley et al., 2013) based on reflection on the consequences and, during the course of the work, could ask him/herself the question "What if..." (Blomhøj and Skånstrøm, 2016), which provided the tasks with elements of openness. Pind (2015) wrote, how open tasks in mathematics teaching were tasks in which there were more possible answers, tasks in which there were choices to be made because there were something not yet decided. In accord with Dewey (1938), the tasks included elements of conscious positioning, whereby the pupil reflected on the consequences of different actions (Artigue and Blomhøj, 2013; Morgan, 2014). It was not merely the choices, but the fact that "...in all the respects mentioned freedom of outward action is a means to freedom of judgement and of power to carry deliberately chosen ends into execution" (Dewey, 1938, p. 63).

It did, however, involve a balance and a cooperative enterprise whereby the teacher gave and took ideas to and from the pupils, as it was possible:

\begin{abstract}
"...to force the activity of the young into channels which express the teacher's purpose rather than that of the pupils. But the way to avoid this danger is not for the adult to withdraw entirely. The way is, first, for the teacher to be intelligently aware of the capacities, needs, and past experiences of those under instruction, and, secondly, to allow the suggestion made to develop into a plan and a project by means of the further suggestions contributed into a whole by the members of the group" (Dewey, 1938, pp. 71-72).
\end{abstract}

The second dimension of inquiry-based science education (Furtak et al., 2012) was then the degree of guidance, described as a continuum between the highly teacher-driven and pupiloriented teaching activities. A detailed instruction for inquiry, or a scientific "kit" offering cookbook instructions, was at the left side of the scale. From these closed tasks a continuum was described, setting pupils increasingly free to make their own decisions concerning inquiry questions and working methods.

Teacher actions supporting inquiry-based learning in practice (Harlen, 2004) are thus important (Furtak et al., 2012), and may require special effort from the teacher, as the teacher is to make space for the pupils' views and suggestions (Michelsen, 2011). Among other things, the teacher must act as a supervisor supporting the pupils' self-employed work without leaving them alone, offering help in the pupils planning so their ideas can be tested appropriately (Harlen, 2004). Through this, the pupils should be offered scaffolding that supports their ideas or presents to them possible strategies that are beyond, or at the border of, their own abilities (Hmelo-Silver et al., 2007), thus widening their perspectives by challenging their inquiry approach. We have added a fourth guidance role, "pupils' inquiry approach widened by the teacher," to the model proposed by Furtak et al. (2012), at the far right of the teacher guidance continuum in Figure 1. The expanded continuum provides us with an analytical approach to understand teachers' work with scaffolding pupils' work and learning in inquiry-based education.

\section{Udeskole in Denmark}

Education outside the classroom in both natural and cultural settings has been recognized to benefit pupils' cognitive, social and physical outcomes (Rickinson et al., 2004; Bamberger and Tal, 2008; Becker et al., 2017; Schneller et al., 2017), the learning outcome often being connected to pupil motivation, hands-on learning and active participation. Outcome assessment highlighted how changing the place of teaching could support pupils in connecting knowledge from school to out-of-school settings (and vice versa), accentuating the long-term nature of pupils' learning. Thus, the out-of-school experiences should not be assessed narrowly based only on the pupils' ability to give correct answers immediately after a teaching sequence, but should take into account long-lasting, adverse, and rich learning outcomes. Although it is not mentioned in the official curricular documents, udeskole is a growing educational practice, performed by a fifth of all Danish schools (Barfod et al., 2016). Emanating from a Norwegian tradition, udeskole has spread to other countries in the northern part of Western Europe (Barfod et al., 2016; Sahrakhiz, 2017). It is a distinct category of outdoor education, held regularly (rather than an occasionally occurring exception), e.g., 1 day a week (Bentsen and Jensen, 2012), led by the schoolteacher herself and not outdoor professionals (Waite et al., 2015), and with a strong curricular content (e.g., Mathematics, History, Science). Thus, the traditional outdoor learning focus shifted "from environmental, personal, social and health perspectives toward curricular perspectives" (Bentsen et al., 2009, p. 38).

Udeskole can be seen as supporting both broad life skills and curricular goals, breaking down the walls of schools, and guiding the pupils' into society (Bentsen and Jensen, 2012). Udeskole research suggested that it was not simply the variation in place (e.g., going outdoors) but also the accompanying variation in teaching approach that constituted the potentials of udeskole (Jordet, 2010). Udeskole was described as an outdoor practice that involved problem-solving, explorative and practical approaches, and constructive, creative and playful approaches, with a necessary connection between the indoor and outdoor lessons (Jordet, 2010; Bentsen and Jensen, 2012), whereby teachers were inspired by the experiential educational tradition (Bentsen and Jensen, 2012). Taking into account that the academic field of udeskole is limited, all this indicates that udeskole holds the potential for learning through inquiry as it opens up for pupils answering their own questions.

There is a lack of knowledge concerning teaching approaches in the outdoors, albeit descriptions of activity categories (e.g., Lindemann-Matthies and Knecht, 2011) and descriptions of how teachers' beliefs affected their teaching in the outdoors (Glackin, 2016) has been published. As teaching outside opens up for new teaching rhythms, themes and methods (Sahrakhiz, 2017), in vivo studies of teaching could qualify an understanding of udeskole practice (Bentsen and Jensen, 2012). This research intends to fill this gap by firstly discussing the understanding of inquirybased teaching and proposing an analytic framework, secondly by 


\section{$\begin{array}{llll}\begin{array}{l}\text { Teacher provided inquiry } \\ \text { strategy }\end{array} & \begin{array}{l}\text { Teacher scaffolding } \\ \text { pupils' inquiry strategy }\end{array} & \begin{array}{l}\text { Pupils perform their own } \\ \text { inquiry approach }\end{array} & \begin{array}{l}\text { Pupils' inquiry approach } \\ \text { widened by the teacher }\end{array}\end{array}$}

FIGURE 1 | Continuum of teacher guidance in inquiry-based teaching. Inspired by Furtak et al. (2012, p. 306).

TABLE 1 | Characteristics of participating teachers and the schools where they work.

\begin{tabular}{llllll}
\hline Participant & P1 & P2 & P3 & P4 & P5 \\
\hline Age & 40 & 43 & 44 & 41 & 45 \\
Gender & Female & Female & Female & Male & Male \\
Years of teacher experience & 14 & 15 & 10 & 14 & 18 \\
Years working with udeskole & 2 & 6 & 10 & 6 & 6 \\
Place & SY & C & CP & SY & SY/CP \\
Pupil age (years) & $9-10$ & $10-11$ & $8-9$ & $10-11$ & $10-11$ \\
Subjects & Ma & Ma, S & Ma, S & Ma & Ma, S \\
Observations, number of days & 7 & 5 & 5 & 6 & 5 \\
\hline
\end{tabular}

SY, Schoolyard and nearby surroundings; $C$, campsite in nature; $C P$, teacher choosing place according to content; e.g., Museum, Lake, Forest.Subjects taught outside. Ma, Mathematics; S, Science.

using this framework to analyze the prevalence of inquiry-based teaching conducted by five teachers in udeskole.

\section{METHODS}

\section{Approach}

To get in-depth insight into individual teachers' intentions and practice in teaching udeskole, a qualitative case study approach was chosen. Five trained teachers representing different forms of udeskole were studied through participant observation (Gold, 1958) over the course of a school year. Field notes observation studies and discussions gave a rich body of material that was then thoroughly analyzed.

\section{Participants}

The participating teachers represented a group of experienced professional teachers for whom udeskole was as an everyday working experience. See Table 1 for the characteristics of participating teachers and the schools where they worked.

Participant 1: Taught mathematics outside in the observed class for 2 lessons lasting 45 min every week (or every second week). She had not attended any outdoor courses at all. This participant worked at a town school, with approximately 400 pupils.

Participant 2: Taught mathematics and science outside in the observed class 1 day every week. She did some work as a consultant, inspiring colleagues to teach science outside. This participant worked at a suburban school with approximately 750 pupils.

Participant 3: Taught mathematics and science outside in the observed class 1 day a week year-round in nearby natural environments, and visited the nature school with guided tours. She attended a 5-day course during her basic education 3 years prior to the observation period. This participant worked at a small rural town school with approximately 150 pupils.

Participant 4: Taught mathematics in the observed class two lessons ( $45 \mathrm{~min}$ each) every week, in the schoolyard. The participant was one of the school's two "learning by movement" consultants. This participant represented a "deviant case" (Silverman, 2013), as his urge for outdoor activities emerged from the school board enrolling in a physical activity program. This participant worked at a small town rural school with approximately 780 pupils.

Participant 5: Taught mathematics outdoors with the observed class in $2 \mathrm{~h}(120 \mathrm{~min})$ lessons 2 days a week. In the years before this study, he conducted outdoor teaching one full day a week. He attended a 5-day "teaching outside with non-formal learning environments" course a few years before the data collection, and attended outdoor network meetings twice a year. This participant worked at a small town school with approximately 110 pupils.

The pupils were not formally participants in the study of the teaching, but they were the recipients of the teaching. The focus in this study was the exercised teaching actions performed by the teacher. When the pupils' reactions were illustrative in understanding the teaching, they were presented anonymized as "a pupil" in the Results section.

\section{Data Collection}

Observations were carried out as participant observation, for a total of 28 days (Gold, 1958) on outdoor lessons planned by the teacher (Silverman, 2013). Each visit lasted 120-420 min, and many of these udeskole days were a combination between outdoor and indoor activities. During the visits, walk-along interviews and conversations with the teachers were noted. Field notes were taken during the lessons and photos were taken to support the researcher's memory. Within two working days, all field notes were rewritten into text files and preliminarily coded into models based on Bamberger and Tal (2007) and Jordet (2010).

All participants gave their informed written consent, and all parents gave written permission to take photos. This project did not require formal ethical approval under Danish legislation.

\section{Analysis}

Prior to analysis, each teaching session was divided into separate incidents; that is, teaching activities initiated by the teacher with a purpose, a beginning, and an end. As the concept of inquiry was broadened, non-linear and explorative teaching approaches were included in the IBSE "orientation" phase and used as an analytic frame. Observational data was organized using the software NVivo QSR. 
An incident was regarded as inquiry-based if it contained each of these following characteristics:

- One or more IBSE phases (Pedaste et al., 2015) leading to other phases,

- An open exploration or open-ended questions with uncertain process and results with open, multiple solution strategies,

- The presence of choices conducted by pupils, and

- The teacher's role being coded as $2-4$ in the following categories.

Inspired by Furtak et al. (2012), the teachers' roles during the inquiry-based incidents were coded into the categories:

4. Teacher widening the pupils' inquiry approach

3. Teacher not interfering with the pupils' performance during the inquiry

2. Teacher scaffolding pupils during the inquiry

1. Teacher instructing pupils in the inquiry task

As the teachers could differentiate their teaching by the degree of guiding different groups of pupils, some incidents could be either "scaffolded" (Category 2) for some students, or "widened" (Category 4) by the teacher for others. The highest degree of challenge observed during the incidents were those categorized here. Activities being performed by the pupils as recurring habits (e.g., measuring weather data) was analyzed as scaffolded, as they were built upon the teacher's ideas but became a skill. As teacher-driven gamelike activities did not offer the pupils any choices connected to process or result, they were categorized as non-inquiry activities (Category 0). The analytic framework is summarized in Table 2.

\section{RESULTS}

\section{Results}

In this chapter, we firstly present an overview of the results as a table. Secondly, we give examples of the different categories, to open the possibility for the reader to get a deeper insight in the basic data.

The main result was, that approximately half of the observed incidents were categorized as inquiry-based. As shown in Table 3, $52 \%$ of all teaching incidents during the 28 observed udeskole days were either in category 4, 3, or 2 of the developed analytic frame.

The analytic frame we developed took into account the cognitive processes offered to the pupils by the teacher. Based on a theoretical background on inquiry-based teaching inspired mainly by Artigue and Blomhøj (2013) and Furtak et al. (2012), we developed an analytic framework only categorizing tasks as inquiry-based if the pupils were offered choices and decision-taking during the process. Even if the pupils were examining or experiencing tasks in the outdoors, but the lessons were teacher led, the activities were not designated as inquiry-based. As all tasks on the observed days were analyzed, non-inquiry activities as training activities and plays and games were observed and categorized (category 0 ).
TABLE 2 | Overview of analytic categories.

\begin{tabular}{ll}
\hline Main category & Description \\
\hline $\begin{array}{l}\text { 4: Teacher widening the pupils' } \\
\text { inquiry approach }\end{array}$ & $\begin{array}{l}\text { The teacher use productive questions to } \\
\text { facilitate the pupils to extend their inquiry } \\
\text { activity }\end{array}$ \\
$\begin{array}{ll}\text { 3: Pupils working without teacher } \\
\text { interference }\end{array}$ & $\begin{array}{l}\text { Pupils autonomously perform their own } \\
\text { inquiry activity }\end{array}$ \\
2: Teacher scaffolding pupils' inquiry & $\begin{array}{l}\text { The teacher guides the pupils in their } \\
\text { inquiry activity through instructive dialogue }\end{array}$ \\
1: Teacher instructing pupils & $\begin{array}{l}\text { The teacher directly guides the pupils } \\
\text { inquiry activity through instructions }\end{array}$ \\
0: Activities with no sign of inquiry & $\begin{array}{l}\text { The teacher leaves no options for choices } \\
\text { for the pupils }\end{array}$
\end{tabular}

TABLE 3 | Portion of incidents coded as inquiry-based, $n=71$.

\begin{tabular}{llll}
\hline Main category & & $\begin{array}{l}\text { Observed } \\
\text { incidents } \boldsymbol{n = 7 1}\end{array}$ & \% of $\boldsymbol{n}$ \\
\hline Inquiry-based & $\begin{array}{l}\text { 4: Teacher widening the } \\
\text { pupils' inquiry approach }\end{array}$ & 52 \\
& $\begin{array}{l}\text { 3: Pupils working without } \\
\text { teacher interference }\end{array}$ & 6 & \\
& $\begin{array}{l}\text { 2: Teacher scaffolding } \\
\text { pupils' inquiry }\end{array}$ & 23 & 48 \\
1: Teacher instructing pupils & 10 & \\
0: Activities with no sign of & 24 &
\end{tabular}

Numbers 1-4 refer to teacher guidance categories in the Methods section. Numbers 1-0 illustrates activities that are not inquiry-based.

\section{Category 4. Teacher Widening the Pupils' Inquiry Approach}

In this paragraph, we describe an example of a teaching incident, where the teacher was widening the pupils' inquiry approach. The teacher supported the pupils' inquiry, and asked them questions during the process to widen their exploration and understanding of their own questions.

On a windy summer day, pupils were working with distance and speed, one of the activities being "bug race," calculating invertebrates' speed in meters per second. The pupils had caught various woodlice, spiders, and earwigs to compete. But the animals were very slow, or ran in too many directions to measure. After trying this out, one pupil suggested how to make them run properly- "We could try to feed them"-and another pupil suggested "Maybe we could measure only ten centimeters?" The teacher challenged these ideas, asking "How can you calculate the speed in meters per second if you only measure ten centimeters?" and "How many centimeters do you have in a meter," and listened to the pupils' suggestions. Numbers were drawn on the ground, and decimal points shifted. Here, the teacher was widening the pupils' inquiry.

Another day, pupils had to work with symmetry, building symmetrically with materials provided by the janitor. Behind the school, there were different building materials as logs, tiles 
and a pile of gravel. The teacher showed with help from a pupil what the task was, to build symmetrically over a symmetry axis drawn with chalk. The children began to work-with their imagination and with symmetry. Either by dividing symmetrical things with the chalk line, or finding two identical things and putting them alike. They also used professional language: "We are building his stomach symmetrically." The janitor had offered many different things, the pupils could go in and pick upchairs, gravel, tiles, circles, and the teacher brought a whole bag of $1 \mathrm{~m} /, 1 / 2$ and $1 / 4 \mathrm{~m}$ sticks the pupil had made before. Gradually all the pupils-more or less-got started. There were many professional and aesthetic discussions between the pupils. Some children build a complicated figure and the teacher draw a new symmetry axis perpendicular to the old. The pupils were discussing, they measured whether the pins were equal long, and they developed the figure, e.g., two boys began to build in height. A group builded an ant of, among other things, wooden slices, and stroke them with sticks in a rhythmic drummer. Some pupils found it difficult to work together, but when they saw how exciting the other group's products were, they got started. At the end of the lesson the teacher gathered all the pupils, asking them what a symmetry axis was-and several fingers came up, but when the explanations came, the students explained symmetry, not symmetry axis. The teacher explained: "It is the line, the white chalk line, the symmetry axis," linking the term with the pupils' own experience and actions.

\section{Category 3. Pupils Working Without Teacher Interference}

In this category, both "orientation phase" (Bybee et al., 2006) and the teachers role "pupils working without teacher interference" is merged. In this paragraph, we first describe an example of an incident, where the teacher did not interfere with the pupils' inquiry. The pupils explored relevant elements of nature, but without any questions set by the teacher. Secondly, we present an example of an incident, comprising one of the IBSE phases (Pedaste et al., 2015), and coded as "orientation phase" in terms lend from Bybee et al. (2006). The class walked to a nearby lake. After receiving safety instructions, the pupils were set free to catch water creatures. Once every $10 \mathrm{~min}$, the teacher yelled "TIME!" and the waders, limited in number, was handed over to other students. The pupils worked unsystematically, but highly engaged, and experienced many different animals; without any conflicts between the pupils. No one used the identifying sheets or the books that were present. Some of the pupils wandered over to nearby trees, which they started to climb. The teacher stood in the lake, as a human border between the shallow and deep water, but did not interfere with the pupils' experiences and discoveries. Here, the pupils performed their own inquiry.

On a cold November day, the pupils had been working drawing a map of the area at a 1:100 scale. The teacher called the pupils; it was now to prepare soup over the bonfire, the bonfire being lit by today's fire team. "Who's going to cut the carrots?" the teacher asked, and the pupils volunteered to contribute to the common project in different ways. As the soup was ready,

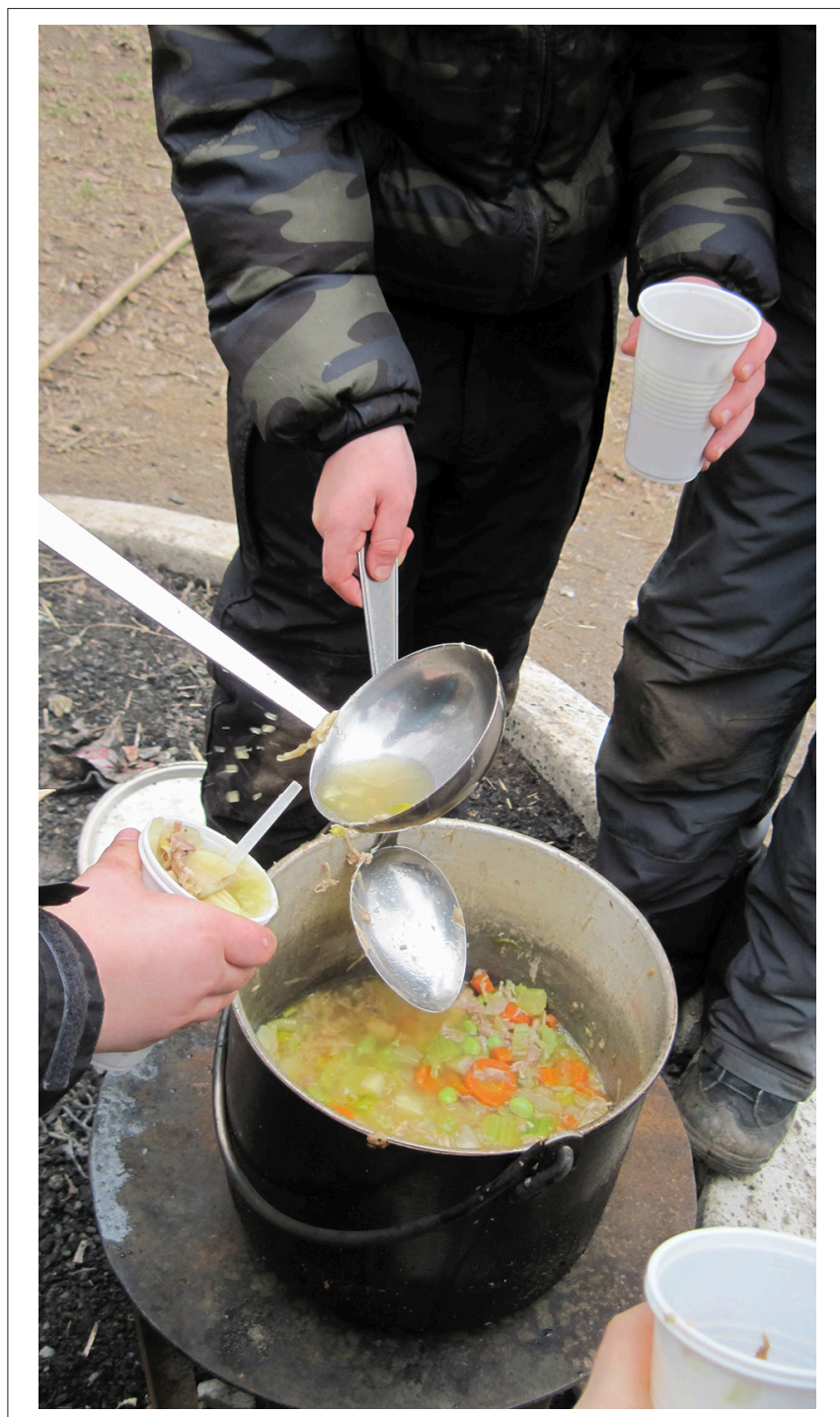

FIGURE 2 | Example from category 3, pupils assesing quantety by sharing the soup.

the pupils lined up and one started to ladle the warm soup into the cups being held out. Only a heeltap was left over for seconds (Figure 2).

When soup was made for the whole class, there had be enough for everyone and at the same time no food waste. The pupils worked with quantities and fractions without explicitly hypothesizing or questioning, instead doling it out by eye. There was a task to be solved involving a rough assessment of quantity, which could serve as a resonance ground for the development of further work with fractions. Here, the pupils performed their own experience-based inquiry.

\section{Category 2. Teacher Scaffolding Pupils' Inquiry}

In this paragraph, we describe an incident, where the teacher did frame the pupils work by scaffolding their inquiry process. The teacher did set the questions to be worked with, but left 
openings for the pupils to make their own choices during the process.

Before working with mathematical equations, pupils were asked to balance wood blocks in the sandbox. The teacher explained the task: "You have to make an equilibrium with these blocks; maximum 10 blocks." The children worked togetherthere was a great deal of cooperation involving, for example, placing blocks on the plank simultaneously (Figure 3). The pupils build huge and beautiful balanced structures, and the teacher provided the groups with supplementary challenges like "Can you make an equilibrium with two blocks on one side and three on the other?", encouraging the pupils to work with the size and placement of the blocks. In this situation, the teacher was scaffolding the pupils' inquiry.

On a cold winter day the teacher entered the classroom with thermometres. The engagement in the class was very low, the air bad and the pupils lethargic. "What do you use these for?" she asked the class. A forest of hands rose: "To measure hot and cold with" is one of the answers. The teacher sat the framework for the activity outside, the task was to measure the temperature at least four different places outside, and at least one place inside. She did not hand out the thermometers, the pupils should pick them up at her desk and bring paper and pen. The pupils immediately started measuring when they came out. Many comments showed how committed they were: "We need to find a place where we can write-we found water there were zero degrees hot," "We have a ball with a hole we can measure in." "We will measure in a dogpooh." A girl wondered what the temperature would be high up in the air, and crawled at the top of the play tower.

The pupils seemed to appreciate getting out, they played in the mud, jumped and crawled, and used their bodies in many ways. Compared to the non-energy that was inside, this was completely different. The pupils had to write down their measurements, but some pupils forgot their paper and pen inside. After an hour, the teacher called the pupils in, and in front of the blackboard a teacher centered summation was done. Where did the groups measure? What did they find?

This day, the teacher had a defined aim with the outdoor lesson, and sat the frames for it-the pupils should measure temperature. But there were still room for the pupils to inquire and choose where to measure, and under which circumstances. By this, the teacher scaffolded the pupils inquiry.

\section{Categories 1 and 0. Activities Not Categorized as Inquiry}

In this paragraph, we describe a teaching incident, where the teacher asked the problem to be examined, and instructed the pupils on how to work. We categorized this group of activities as teacher instructing pupils in the inquiry task. There was no choices left to be taken by the pupils. Activities of this kind is not categorized as inquiry-based in our analysis. In this case, the pupils have to collect data for a bar graph illustrating running time, each pupil running one defined roundtrip in the nearby environment. The teacher started them off by counting down, and asked them to read their own time on the iPad. When they got their time they had to take the stone that represented them and place it on the correct bar. The pupils were instructed exactly what to do, and had no choices regarding the inquiry outcome beyond running quickly or slowly.

On some occasions, teachers chose work involving the repetition of subject-related content, e.g., letting the pupils play a game with given rules, with the tasks instructed by the teacher. We categorized these as training activities. Running around trying to catch a matching card (e.g., I have a card with the value $1 / 4$ and you have one with 0.25 , so we need to find each other and match up), challenging the pupils' ability to work together, to run, and to figure out game-related strategies. This instructive practice was specifically the most abundant with participant four, the "movement in learning" consultant (results not shown). In the observations it was evident that a tail of pupils pestered the

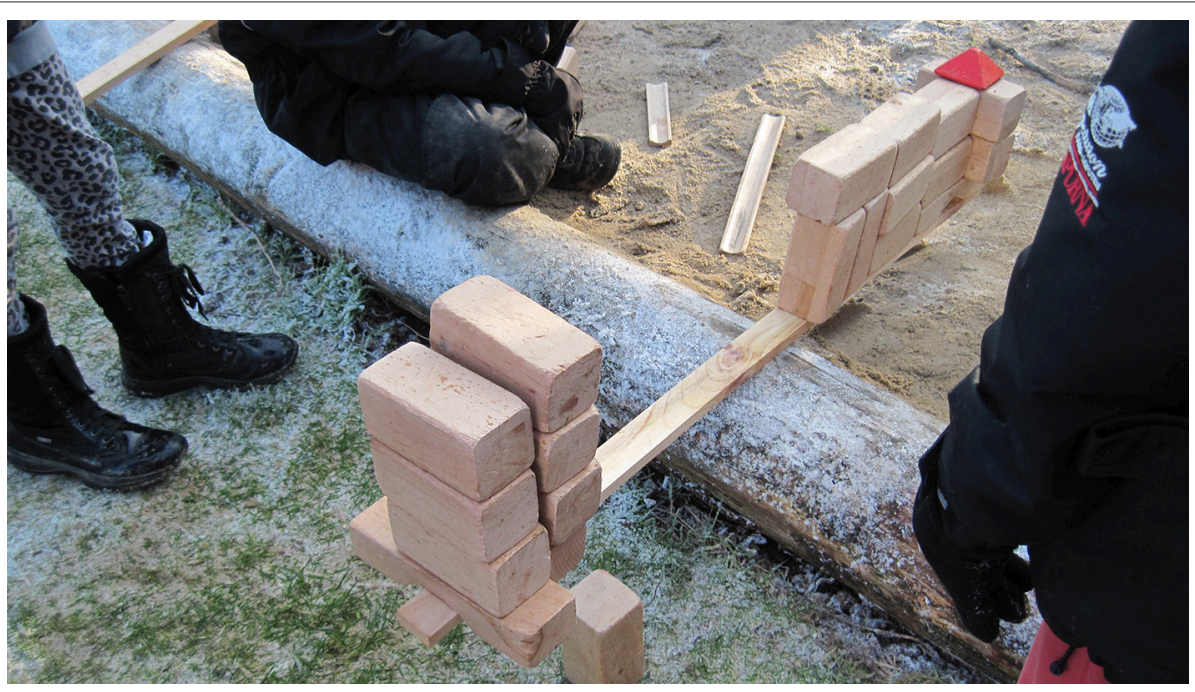

FIGURE 3 | Example of category 2, pupils balancing wooden blocks. 
teacher during the closed tasks, asking "What should I do now?" and "Is this good enough?", paying attention to the only one correct answer. On the occasions when visits to the nature center were observed, the nature guides, although they were genuinely good storytellers, did not develop the children's ability to figure out problem-based solutions, but mostly either told them how to do the tasks or simply told them good stories.

\section{DISCUSSION}

This study seems to indicate, that for the studied five teachers, about half of the teaching in udeskole involved non-instructive, inquiry-based activities for pupils aged 8-11 years. Observations of naturally occurring outdoor science and mathematics lessons by these 5 teachers exposed both closed training tasks and open-ended, inquiry-based tasks. We developed a framework to analyze udeskole practice, inspired both by IBSME and free-choice learning. Firstly, we added experience and sensory perceptions to the orientation phase in IBSME. Secondly, we excluded the teacher-instructed, nonchoice teaching sessions from the inquiry category. This gave us two main categories of teaching practice outside the classroom: inquiry-based and non-inquiry-based. The framework for analyzing the teaching as inquiry-based took into account:

"[...] the development of problem-solving abilities and inquiry habits of mind; the autonomy and responsibility given to pupils, from the formulation of questions to the production and validation of answers; the guiding role of the teacher and teacherpupil(s) dialogic interactions; and [...] the critical and democratic dimensions of IBME” (Artigue and Blomhøj, 2013, p. 809).

This is in agreement with Nesbit and Qing (2014) emphasizing not only the questioning part of pupils' inquiry, but also the experiences and explorations as a base for their construction of knowledge. Still, we did not count incidents in which the teacher instructed as inquiry, as these left pupils with few or no options for making choices. In contrast to the BSCS $5 \mathrm{E}$ system launched by Bybee et al. (2006), the incidents analyzed here were much shorter in duration, and the inquiry was often reduced to one or two lessons. The strength in this is that it was manageable for the teacher to teach outdoors on a daily school day, without having to break the schedule up for a longer period, while still retaining some of the qualities of inquiry. By doing this, we acknowledged the structured inquiry approach in IBSME and the BCBS 5E system, but widened it by recognizing explorative investigations as inquiry while also narrowing it by excluding closed, teacher-instructed tasks.

Udeskole (Bentsen et al., 2009) does not necessarily imply inquiry-based teaching, even if this small-scale study points to a great deal of this approach. Assessing the effect of udeskole must take into account the actual performed approach to teaching, taking care to closely examine the teaching performed, while not taking for granted that the place of teaching automatically implies a specific teaching approach.
Indeed, teachers frequently needed training in order to give their pupils the freedom to build their own knowledge (Tavares et al., 2015). This was supported by the notion, that inquiry-based programs based on scientific kits had no effect on science achievement measures. This was likely because the teacher expended more effort on using the kit than on developing inquiry habits of mind, compared to programs developing teachers' generic competences in engaging and motivating pupils working with collaborative tasks, conceptual challenges, and inquiry approaches (Slavin et al., 2014).

Whenever teachers opened for methodological pluralism, pupils could continue to experience excitement at solving a question or problem on their own, or as part of a team (Tavares et al., 2015). In udeskole, there were many approaches to inquiries with curricular aims. In the presented cases, the pupils worked independently of the teacher during non-instructed tasks, and the teachers' role and communication with the children were less judging. By taking a more listening attitude to the proposals from the children, and discussing their solutions with them, the teacher could manage to encourage them to pursue their own interests and challenge them cognitively. This is the case in our "widening" category 4, where it was the teacher's challenging questions that stimulated the pupils to elaborate on their inquiry activity. In our "autonomous" category 3, the pupils worked without teacher interference, presumably driven by their own ideas and intrinsic motivation (Saunders-Stewart et al., 2012), but also limited by it. In our "scaffolding" category 2, the pupils needed the teacher's assistance and support in order to work purposefully with the inquiry activity.

In our analyzed cases, a common activity was allowing the pupils to get experiences with materials in order to create a foundation for understanding. In the equationbalancing blocks task, the pupils activated a common human experience with balance and the teacher later used this to work with equations, thereby connecting the pupils' experience with school mathematics content (Bamberger and Tal, 2008).

This study concerns teaching options outside the classroom, in settings that offered more than classic scholastic sensory perceptions from, e.g., nature or everyday objects. Teachers must be aware of how this expansion of educational place and experience should make learning coherent, since:

\footnotetext{
"as an individual passes from one situation to another, his world, his environment expands or contracts [relational experiences]. [...] What he has learned in the way of knowledge and skill in one situation becomes an instrument of understanding and dealing effectively with the situations, which follows [continuity of experiences]" (Dewey, 1938, p. 44).
}

The reference to personal environment here refers to relational experiences-e.g., learning with others-and the reference to a following situation refers to the continuity of experiences-e.g., addressing formerly acquired learnings in preparing, or during, the inquiry. 


\section{LIMITATIONS}

This study is limited in several ways, one of which is the periodic nature of the observations. As mentioned by Bybee et al. (2006), an inquiry process can take several weeks; however, the observations in this study were only conducted on approximately a monthly basis. That is, in some cases the observations may only show one phase, or part, of the educational process. Conversations with the teachers during the sessions and email correspondence contextualized the incidents, leading to the coding category "the incident contains one or more phases leading to more phases" being included as part of the inquiry process. Still, we acknowledge even shorter incidents containing, e.g., open-ended tasks with uncertain process and result with open, multiple solution strategies such as "the development of problem-solving abilities and inquiry habits of mind" (Artigue and Blomhøj, 2013, p. 809).

The same researcher performed the observations and analysis in this study. This can be seen as both a strength and a weakness: a strength, as the analyzer worked closely with the teachers and teaching, so that the field notes and photos were not the only source of information; and a weakness, as bias-due to the data being seen from only one angle, that of the observer-can hide blind spots. This was addressed by thoroughly discussing the analysis between the two authors, and examining the photos and examples during the writing process.

The significance of the philosophical and traditional underpinnings of the educational context varying between countries limits our ability to generalize. Still, this contextualized study can contribute to an extended discussion of the educational value of pupil-centered teaching approaches outside the classroom; in this case, udeskole.

\section{CONCLUSION}

In this article, 28 days of naturally occurring $u$ deskole lessons were observed, and all 71 teaching incidents outside the

\section{REFERENCES}

Albrechtsen, T. R. S., and Qvortrup, A. (2017). Undersøgelsesbaseret Undervisning: Et Review Over Nyere forSkningslitteratur Fra et Almendidaktisk Perspektiv. (Inquiry-Based Teaching. A Review of Recent Research Literature From a Didactical Perspective). Danish University Colleges. [In Danish]. Available online at: https://www.ucviden.dk/ws/files/47008439/KiDM_delrapport_1_ ISBN.pdf

Artigue, M., and Blomhøj, M. (2013). Conceptualizing inquiry-based education in mathematics. ZDM 45, 797-810. doi: 10.1007/s11858-013-0506-6

Artigue, M., Dillon, J., Harlén, W., and Léna, P. (2012). Learning Through Inquiry. Retrieved 6.11.2017. Available online at http://www.fibonacci-project.eu/

Bamberger, Y., and Tal,. T. (2007). Learning in a personal context: levels of choice in a free choice learning environment in science and natural history museums. Sci. Educ. 91, 75-95. doi: 10.1002/ sce. 20174

Bamberger, Y., and Tal, T. (2008). Multiple outcomes of class visits to natural history museums: the students' view. J. Sci. Educ. Technol. 17, 274-284. doi: $10.1007 /$ s10956-008-9097-3 classroom were analyzed in relation to inquiry-based teaching. We found three categories of teaching supporting pupils' inquiry in udeskole and their choice options in the inquiry process. These categories were when the teacher scaffolded the pupils during the inquiry; when the teacher did not interfere with the pupils' performance during the inquiry; and when the teacher widened the pupils' inquiry approach. Beside this, the concept of inquirybased teaching used here acknowledged how an inquiry process could be started in multiple ways, including experience-based approaches. In this understanding, about half of the observed teaching incidents in udeskole were categorized as inquiry-based. The results showed that teaching outside the classroom in udeskole has the potential to let pupils work inquiry-based (in our understanding of the term inquiry), thus paving the way for a child-activating education in science and mathematics.

\section{AUTHOR CONTRIBUTIONS}

KB has contributed to the design of the study, collected all data, and contributed significantly to the analysis and the draft of the manuscript. PD has taken part in the analysis, and contributed substantially to the interpretation of the data and to the final writing. Finally, both authors have approved the manuscript for consideration, and account for all aspects of the presented work.

\section{FUNDING}

VIA University College has provided the authors as employees.

\section{ACKNOWLEDGMENTS}

Thank you to all participating teachers who shared their time and opened their classroom doors to us. Thank you to all senior researchers and students in the TEACHOUT study at Copenhagen University, and to our colleague Arne Mogensen at VIA for the fast and thoughtful comments. Thank you to VIA University College for financing this study.

Barfod, K., Ejbye-Ernst, N., Mygind, L., and Bentsen, P. (2016). Increased provision of udeskole in Danish schools: an updated national population survey. Urban Forestry Urban Greening 20, 277-281. doi: 10.1016/j.ufug.2016.09.012

Becker, C., Lauterbach, G., Spengler, S., Dettweiler, U., and Mess, F. (2017). Effects of regular classes in outdoor education settings: a systematic review on students' learning, social and health dimensions. Int. J. Environ. Res. Public Health 14:485. doi: 10.3390/ijerph14050485

Bentsen, P., and Jensen, F. S. (2012). The nature of udeskole: outdoor learning theory and practice in Danish schools. J. Adv. Educ. Outdoor Learn. 12, 199-219. doi: 10.1080/14729679.2012.699806

Bentsen, P., Mygind, E., and Randrup, T. B. (2009). Towards an understanding of udeskole: education outside the classroom in a Danish context. Education 3-13 37, 29-44. doi: 10.1080/03004270802291780

Blomhøj, M., and Skånstrøm, M. (2016). "Det kommer an på, in Matematikkloering for Framtida, eds H. Alrø and T. E. Rangnes (Norway: Caspar Forlag), 87-99. [In Danish].

Braund, M. (2004). "Learning at museums and hands-on centres," in Learning Science Outside the Classroom, eds M. Braund and M. Reiss (New York, NY: RoutledgeFalmer), 113-128. 
Bromley, G., Regan, E., Kapelari, S., Dillon, J., Vergou, A., Willison, J., et al. (2013). The INQUIRE Course Manual. London: BGCI.

Bybee, R. W., Taylor, J. A., Gardner, A., van Scotter, P., Carlson Powell, J., Westbrook, A., et al. (2006). The BSCS 5E Instructional Model: Origins and Effectiveness. Colorado Springs: BSCS.

Dewey, J. (1938). Experience and Education. New York, NY: Kappa Delta Phi.

Falk, J. H. (2005). Free-choice environmental learning: framing the discussion. Environ. Educ. Res. 11, 265-280. doi: 10.1080/135046205000 81129

Furtak, E. M., Seidel, T., Iverson, H., and Briggs, D. C. (2012). Experimental and quasi-experimental studies of inquiry-based science teaching: a meta-analysis. Rev. Educ. Res. 82, 300-329. doi: 10.3102/0034654312457206

Glackin, M. (2016). 'Risky fun' or 'Authentic science'? How teachers' beliefs influence their practice during a professional development programme on outdoor learning. Int. J. Sci. Educ. 38, 409-433. doi: 10.1080/09500693.2016.1145368

Gold, R. L. (1958). Roles in sociological field observations. Soc. Forces 36, 217-223. doi: $10.2307 / 2573808$

Harlen, W. (2004). Evaluating Inquiry-Based Science Developments. Los Angeles; London; Singapore; Washington, DC. Available online at: http://stem. gstboces.org/Shared\%20Documents/STEM\%20DEPLOYMENT\%20PROJECT \%20RESEARCH/NAS_paper_eval_inquiry_science.pdf (Retrieved November 2017).

Hmelo-Silver, C. E., Duncan, R. G., and Chinn, C. A. (2007). Scaffolding and achievement in problem-based and inquiry learning: a response to Kirschner, Sweller, and Clark (2006). Educ. Psychol. 42, 99-107. doi: $10.1080 / 00461520701263368$

Hwang, S., and Roth, W. M. (2011). Scientific and Mathematical Bodies: The Interface of Culture and Mind. Rotterdam; Boston, MA; Taipei: Springer Science and Business Media.

Jordet, A. N. (2010). Klasserommet Utenfor. Tilpasset Opleering $i$ et Utvidet Laringsrom. [The classroom outside. Customized Training in an Extended Learning Space]. Oslo:Cappelen akademiske [In Norwegian].

Katz, I., and Assor, A. (2007). When choice motivates and when it does not. Educ. Psychol. Rev. 19, 429-442. doi: 10.1007/s10648-006-9027-y

Leat, D. (eds) (2017). Enquiry and Project Based Learning - Students, School and Society. London: Routlegde.

Lindemann-Matthies, P., and Knecht, S. (2011). Swiss elementary school teachers' attitudes toward forest education. J. Environ. Educ. 42, 152-167. doi: 10.1080/00958964.2010.523737

Michelsen, C. (2011). IBSME - Inquiry-based science and mathematics education. MONA 72-77 [In Danish].

Morgan, D. L. (2014). Pragmatism as a paradigm for social research. Qual. Inq. 20, 1045-1053. doi: 10.1177/1077800413513733

Nesbit, J., and Qing, L. (2014). Is Inquiry-Based Learning Effective? The Facts on Education. Canadian Education Association and Simon Fraser University, Canada. Available online at: https://www.edcan.ca/wp-content/uploads/CEAFACTS-ON-ED_INQUIRY-BASED-LEARNING.pdf
Pedaste, M., Mäeots, M., Siiman, L. A., de Jong, T., van Riesen, S. A. N., Kamp, E. T., et al. (2015). Phases of inquiry-based learning: definitions and the inquiry cycle. Educ. Res. Rev. 14, 47-61. doi: 10.1016/j.edurev.2015.02.003

Pind, P. (2015). Åben og Undersøgende Matematik (Open and Investigative Mathematics). Skødstrup: Forlaget Pind og Bjerre. [In Danish].

Rickinson, M., Dillon, J., Teamey, K., Morris, M., Choi, M. Y., Sanders, D., et al. (2004). A Review of Research on Outdoor Learning. A Review of Research on Outdoor Learning. Retrieved from http://www.field-studies-council.org/ documents/general/nfer/a_review_of_research_on_outdoor_learning.pdf

Sahrakhiz, S. (2017). The 'outdoor school' as a school improvement process: empirical results from the perspective of teachers in Germany. Education 3-13 1-13. doi: 10.1080/03004279.2017.1371202

Saunders-Stewart, K. S., Gyles, P. D. T., and Shore, B. M. (2012). Student outcomes in inquiry instruction: a literature-derived inventory. J. Adv. Acad. 23, 5-31. doi: $10.1177 / 1932202 X 11429860$

Schneller, M. B., Schipperijn, J., Nielsen, G., and Bentsen, P. (2017). Children's physical activity during a segmented school week: results from a quasiexperimental education outside the classroom intervention. Int. J. Behav. Nutr. Phys. Act. 14:80. doi: 10.1186/s12966-017-0534-7

Silverman, D. (2013). Doing Qualitative Research: A Practical Handbook, 4th Edn. Los Angeles, CA; London; New Delhi; Singapore; Washington, DC: SAGE Publications Limited.

Slavin, R. E., Lake, C., Hanley, P., and Thurston, A. (2014). Experimental evaluations of elementary science programs: a best evidence synthesis. J. Res. Sci. Teach. 51, 870-901. doi: 10.1002/tea.21139

Tavares, A. C., Silva, S., and Bettencourt, T. (2015). "Advantages of science education outdoors through IBSE methodology," in Inquiry-Based Learning for Science, Technology, Engineering, and Math (STEM) Programs: A Conceptual and Practical Resource for Educators, eds P. Blessinger and J. M. Carfora (Bingley, UK: Emerald), 151-169.

Van Uum, M. S. J., Verhoeff, R. P., and Peeters, M. (2016). Inquiry-based science education: towards a pedagogical framework for primary school teachers. Int J. Sci. Educ. 38, 450-469. doi: 10.1080/09500693.2016.1147660

Waite, S., Bølling, M., and Bentsen, P. (2015). Comparing apples and pears? A conceptual framework for understanding forms of outdoor learning through comparison of English forest schools and Danish Udeskole. Environ. Educ. Res. 1-25. doi: 10.1080/13504622.2015.1075193

Conflict of Interest Statement: The authors declare that the research was conducted in the absence of any commercial or financial relationships that could be construed as a potential conflict of interest.

Copyright $\odot 2018$ Barfod and Daugbjerg. This is an open-access article distributed under the terms of the Creative Commons Attribution License (CC BY). The use, distribution or reproduction in other forums is permitted, provided the original author(s) and the copyright owner are credited and that the original publication in this journal is cited, in accordance with accepted academic practice. No use, distribution or reproduction is permitted which does not comply with these terms. 